\title{
Plantas medicinais comercializadas em feiras livres do Estado do Piauí, nordeste do
}

\section{Brasil}

\author{
Medicinal plants sold in open fairs of State of Piauí, northeastern Brazil \\ Plantas medicinales vendidas en mercados abiertos en el Estado de Piauí, nordeste de Brasil
}

Recebido: 06/07/2021 | Revisado: 13/07/2021 | Aceito: 16/07/2021 | Publicado: 27/07/2021

Francielson da Silva Barbosa
ORCID: https://orcid.org/0000-0001-6364-7563
Instituto Federal de Educação, Ciência e Tecnologia do Piauí, Brasil
E-mail: biologofrancielson @ gmail.com
Sâmia Caroline Melo Araújo
ORCID: https://orcid.org/0000-0002-8817-8406
Universidade Estadual do Maranhão, Brasil
E-mail: carolinesamia93@gmail.com
Cledinaldo Borges Leal
ORCID: https://orcid.org/0000-0003-3601-1898
Universidade Federal do Piauí, Brasil
E-mail: cledinaldo@ gmail.com
Etielle Barroso de Andrade
ORCID: https://orcid.org/0000-0002-5030-1675
Instituto Federal de Educação, Ciência e Tecnologia do Piauí, Brasil
E-mail: etlandrade@ @otmail.com

\section{Resumo}

A etnobotânica estuda as relações homem-natureza, buscando informações sobre os usos de plantas e propriedades medicinais. Neste contexto, as feiras livres desempenham um importante papel organizacional e cultural, garantindo a preservação dos costumes e características que a representa. Este trabalho buscou identificar as principais plantas medicinais comercializadas por feirantes livres em três cidades da região do Sudeste Piauiense. A partir de questionário semiestruturado e entrevistas com feirantes nas feiras livres nas cidades de Jaicós, Paulistana e Picos. Foram identificadas 169 espécies de plantas pertencentes a 100 famílias e 11 etnoespécies. A família com maior representatividade foi Fabaceae. A casca foi a parte com maior índice de comercialização em duas das três cidades. As espécies com importância relativa foram endro, copaíba e pixuri. Houve maior semelhança entre as feiras livres de Paulistana e Picos. Todos os estimadores de riqueza apontaram números acima dos registrados para as três cidades, sendo esperado para a cidade de Picos um acréscimo de pelo menos 38 espécies.

Palavras-chave: Etnobotânica; Etnoespécies; Fabaceae; Plantas medicinais; Índice de importância relativa.

\begin{abstract}
Ethnobotany studies human-nature relationships, seeking information on the uses of plants and medicinal properties. In this context, open fairs play an important organizational and cultural role, ensuring the preservation of customs and characteristics that represent them. This work sought to identify the main medicinal plants sold by free marketers in three cities in southeastern of Piauí. From a semi-structured questionnaire and interviews with stallholders in open markets in the cities of Jaicós, Paulistana, and Picos. We identified 169 plant species belonging to 100 families and 11 ethnospecies. The most representative family was Fabaceae. Shell was the part with the highest commercialization index in two of the three cities. The species with maximum value of relative importance were endro, copaíba and pixuri. There was a greater similarity between the free markets in Paulistana and Picos. All wealth estimators pointed to numbers above those recorded for the three cities, with the addition of at least 38 species expected for the city of Picos.
\end{abstract}

Keywords: Ethnobotany; Ethnospecies; Fabaceae, Medicinal plants; Relative importance index.

\section{Resumen}

La etnobotánica estudia las relaciones entre el ser humano y la naturaleza, buscando información sobre los usos de las plantas y sus propiedades medicinales. En este contexto, las ferias abiertas juegan un importante papel organizativo y cultural, asegurando la preservación de las costumbres y características que las representan. Este trabajo buscó identificar las principales plantas medicinales vendidas por comercializadores en tres ciudades del sureste de Piauí. A partir de un cuestionario semiestructurado y entrevistas a comerciantes en mercados abiertos de las ciudades de Jaicós, Paulistana y Picos. Se identificaron 169 especies vegetales pertenecientes a 100 familias y 11 etnoespecies. La familia más representativa fue Fabaceae. La corteza fue la parte con mayor índice de comercialización en dos de las tres ciudades. Las especies de importancia relativa fueron eneldo, copaiba y pixuri. Hubo mayor similitud entre los 
mercados abiertos de Paulistana y Picos. Todos los estimadores de riqueza mostraron cifras superiores a las registradas para las tres ciudades, y se espera un aumento de al menos 38 especies para la ciudad de Picos.

Palabras clave: Etnobotánica; Etnoespecies; Fabaceae; Plantas medicinales, Índice de importancia relativa.

\section{Introdução}

A Etnobotânica tem buscado informações sobre a utilização de plantas com propriedades medicinais, o que tem contribuindo significativamente para o conhecimento e entendimento de como populações vêm utilizando as substâncias extraídas das plantas para tratamento e cura de diversas enfermidades (Lopes et al., 2010). Neste sentindo, a utilização de plantas pelas sociedades não estava restrita apenas ao caráter alimentar, mas também às propriedades de cura, reais ou ritualísticas (Souza-Moreira et al., 2010).

$\mathrm{O}$ uso de plantas com propriedades medicinais tem origem antiga, remontando aos primórdios da medicina, se fundamentando no acúmulo de informações passadas de geração a geração (Brasil, 2006). Assim, as plantas sempre foram a principal fonte de prevenção e tratamento de doenças e são fontes de matéria-prima para a produção medicamentos na medicina moderna (Mowobi et al., 2016). Dessa forma, o termo planta medicinal foi cunhado para designar aquelas que possuem algum efeito sobre uma determinada doença ou sintoma (Di Stasi, 1996). O preparo de remédios caseiros, a partir das plantas, tem aumentado de forma significativa por ser uma forma de tratamento barata e de fácil acesso (Silva et al., 2014), e por isso, a fitoterapia foi reconhecida pela Organização Mundial de Saúde como uma forma alternativa de tratamento de enfermidades (OMS, 2015).

As plantas medicinais, na grande maioria das vezes, são cultivadas nos quintais das residências, principalmente para o preparo de chás e infusões a partir das folhas de plantas herbáceas em função de seu fácil cultivo (Liporacci \& Simão, 2013). Por outro lado, para a extração de cascas, raízes, sementes, frutos e/ou outras partes, é essencial a participação da figura do raizeiro ou mateiro, uma vez que a maioria destes detém um rico conhecimento que é passado de geração em geração, fator decisivo para a etapa de coleta em campo (Nunes et al., 2003). A impossibilidade do cultivo de grande parte de espécies arbóreas nos quintais das residências, induz os usuários a recorrem às feiras livres para adquirirem produtos vegetais extraídos e comercializados por raizeiros ou feirantes livres (Tresvenzol et al., 2006).

No Brasil, relatos da existência das feiras livres atribuem-se a sua existência desde a era colonial. No entanto, mesmo com todos os avanços tecnológicos, a feira livre ainda é um local amplamente visitado pela população, e muitas cidades interioranas a tem como um dos únicos centros de entretenimento e troca de informações (Almeida, 2009). Nesse contexto, as feiras livres desempenham um importante papel organizacional e cultural, garantindo a preservação dos costumes e características que a representa (Boechat \& Santos, 2015). Além disso, as feiras livres são fonte de renda e troca de informações, contribuindo significativamente para a manutenção da diversidade de saberes populares de um povo, bem como a sua continuidade (Souza, 2015).

Dentro desta temática, realizou-se um levantamento etnobotânico das plantas medicinais que são comercializadas em feiras livres de três cidades do Sudeste Piauiense, Nordeste do Brasil, analisando: (i) as principais espécies de plantas e os diversos usos na medicina tradicional; (ii) quais as partes das plantas são mais utilizadas, bem como as indicações e contraindicações dos tratamentos alternativos; (iii) a importância relativa das espécies de plantas medicinais comercializadas; (iv) a estimativa de riqueza e a diversidade das plantas comercializadas; e (v) o grau de similaridade no comércio de plantas medicinais entre as diferentes cidades.

\section{Metodologia}

\section{1 Área de estudo}

O levantamento de dados foi realizado entre os meses de agosto e outubro de 2017, nas feiras livres das cidades de 
Jaicós, Paulistana e Picos, localizadas na mesorregião do Sudeste Piauiense (IBGE, 2017) (Figura 1). Estas cidades foram selecionadas em função de concentrar grande parte do comércio da região e serem as cidades polo para diversos municípios da mesorregião em que estão inseridas.

Figura 1. Mapa de localização do estado do Piauí, destacando mesorregião do Sudeste Piauiense e as cidades de Jaicós, Paulistana e Picos, Nordeste do Brasil.

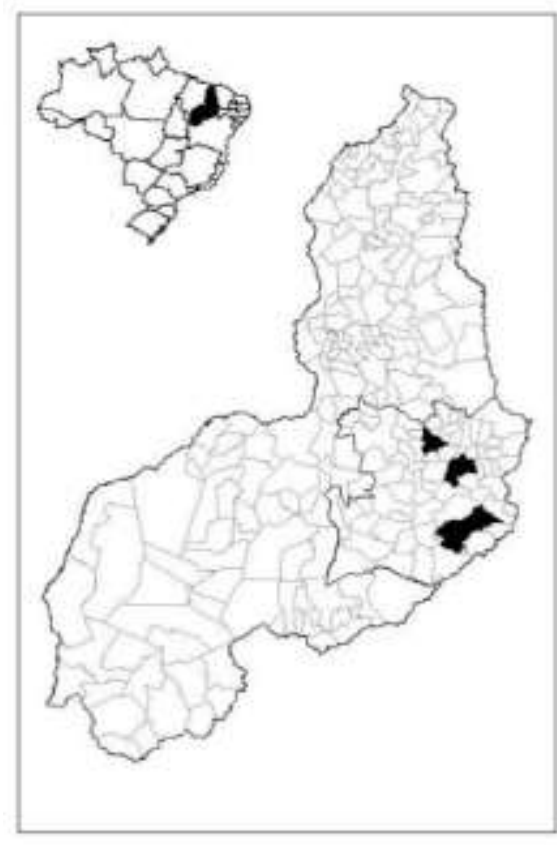

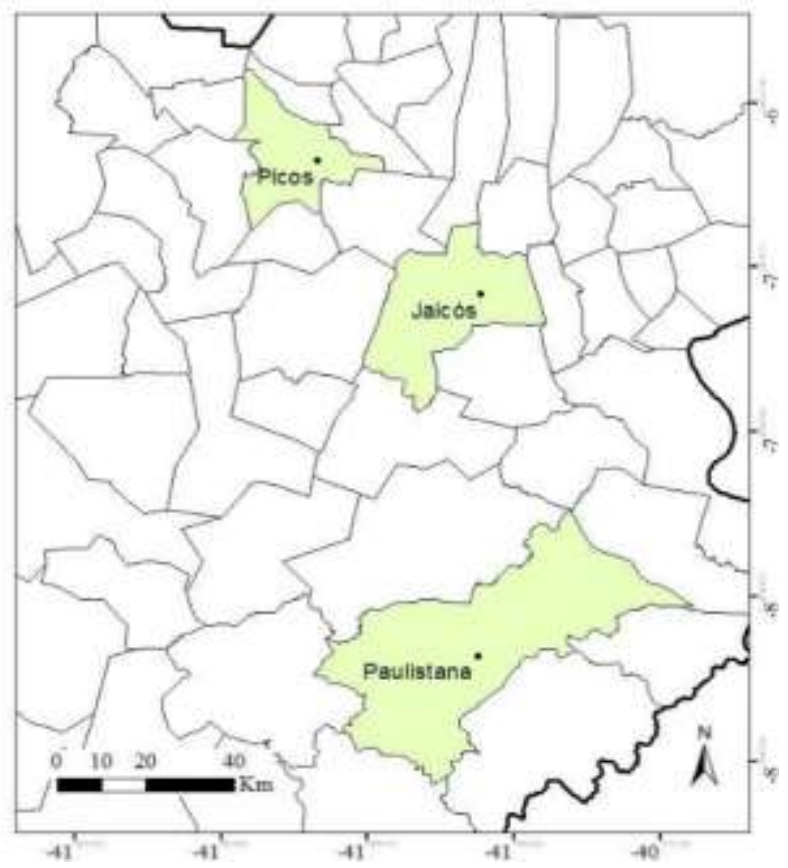

Fonte: Autores.

O munícipio de Jaicós está inserido na microrregião Alto Médio Canindé, entre as coordenadas 4108'16" W e 07²21'33" S. Possui uma população aproximada de 19 mil habitantes (IBGE, 2020) e faz divisa ao norte com os municípios de Campo Grande do Piauí e Francisco Santos, ao sul com os municípios de Patos e Massapê do Piauí, à leste com Belém do Piauí e Padre Marcos, à oeste com Geminiano e Itainópolis.

O município de Paulistana, localizado entre as coordenadas $41^{\circ} 08^{\prime} 59^{\prime \prime} \mathrm{W}$ e $08^{\circ} 08^{\prime} 37^{\prime \prime} \mathrm{S}$, está inserido também na microrregião Alto Médio Canindé e possui uma população aproximada de 20.500 habitantes (IBGE, 2020). Tem como municípios limítrofes as cidades de Queimada Nova e Acauã ao sul, Betânia do Piauí à leste, a cidade de Jacobina do Piauí ao norte, a cidade de São Francisco de Assis do Piauí à oeste.

O município de Picos, localizado entre as coordenadas 4128 $01^{\prime \prime} \mathrm{W}$ e $07^{\circ} 04^{\prime} 37^{\prime \prime} \mathrm{S}$, está inserido na microrregião de Picos e possui uma população aproximada de 78.400 habitantes (IBGE, 2020), ocupando a terceira posição no ranking dos municípios mais populosos do estado do Piauí (CEPRO, 2016). Considerada a capital do mel, possui um dos maiores polos comerciais do estado do Piauí, limitando-se ao norte com os municípios de Santana do Piauí e Sussuapara, ao sul com Itainópolis, à leste faz divisa com os municípios de Geminiano e Sussuapara, à oeste com os municípios de Dom Expedido Lopes e Paquetá do Piauí (IBGE, 2020).

\subsection{Procedimentos de campo}

Para a coleta de dados utilizou-se a técnica de amostragem não aleatória intencional (Ferreira et al., 2012), mediante aplicação de um questionário semiestruturado complementado com entrevistas e conversas informais (Albuquerque et al., 2012) com feirantes nas feiras livres das três cidades. Como critério de inclusão, selecionou-se apenas os feirantes livres que 
comercializavam plantas medicinais ou parte delas (cascas, folhas, sementes, raízes, flores, caules, bulbos, etc.), nas feiras livres das cidades alvo da pesquisa. Foram entrevistados um total de 22 feirantes livres sobre os modos de utilização das plantas medicinais, sendo nove na cidade de Picos, oito na cidade de Jaicós e apenas cinco na cidade de Paulistana.

A partir dos nomes populares fornecidos e do material coletado através da compra ou doação pelos feirantes, foi feito a identificação das famílias e das espécies a partir da comparação de fotografias e/ou partes do material coletado, utilizando para consulta o banco de dados do Missouri Botanical Garden (www.tropicos.org), a Lista de Espécies do banco de dados da Flora do Brasil (www.floradobrasil.jbrj.gov.br) e do Herbário Vale do São Francisco (www.univasf.edu.br).

\subsection{Procedimentos éticos}

As entrevistas e a aplicação de questionários junto aos feirantes foram realizadas somente após submissão e aprovação do projeto junto ao Comitê de Ética em Pesquisa da Universidade Federal do Piauí - CEP, conforme parecer de aprovação (CAAE: 70052017.1.0000.5214).

\subsection{Análises de dados}

As espécies de plantas medicinais ou etnoespécies, termo utilizado quando não foi possível a identificação ao nível específico, sendo reconhecida apenas por um nome popular (Rossato et al., 1999), foram divididas de acordo com as enfermidades tratadas e agrupadas em categorias de acordo com a classificação das doenças da Organização Mundial da Saúde (OMS, 2015), segundo o modelo utilizado pelo Centro Brasileiro de Classificação de Doenças.

Para determinar a importância das espécies citadas quanto a sua utilidade, foi calculado o Valor de Uso (VU), a partir da fórmula $\mathrm{VU}=\Sigma \mathrm{U} / \mathrm{n}$, sendo " $\mathrm{U}$ " o número de citações da espécie/etnoespécie por informante, e "n" indica número de informantes que citaram a espécie/etnoespécie (Rossato et al., 1999). A determinação da variabilidade das plantas em relação a cada tipo de tratamento e o consenso nas informações dos feirantes foi determinada a partir do cálculo do Fator de Consenso Informante (FCI), adaptado de Ferreira et al. (2012). O FCI foi calculado mediante a seguinte fórmula: FCI = nar - na/nar - 1, onde "nar" é o número de citações de usos em cada categoria e "na" corresponde ao número de espécies indicadas em cada categoria (Almeida, 2008). O produto deste fator varia de 0 a 1 . O valor máximo obtido pelo $\mathrm{FCI}=1$ reflete um consenso total entre os informantes sobre espécies medicinais para uma determinada categoria. Um valor mais baixo (próximo de 0) indica que os informantes discordam sobre as indicações de uma planta usada para tratamento de uma determinada doença (Ferreira et al., 2012).

A importância relativa (IR) das plantas medicinais foi calculada de acordo com Bennett e Prance (2000). O cálculo de IR foi feito utilizando a fórmula IR = NSC + NP, onde NSC representa o número de sistemas corporais e NP corresponde ao número de propriedades. Neste caso, o NSC é determinado pela razão entre o número de sistemas corporais tratados por uma determinada espécie (NSCE) e o número total de sistemas corporais tratados pela espécie mais versátil (NSCEV), calculado de acordo com a seguinte fórmula: NSC = NSCE/NSCEV. O NP por sua vez, é determinado pela razão entre o número de propriedades atribuídas a uma determinada espécie (NPE) e o número total de propriedades atribuídas à espécie mais versátil (NPEV), tendo como fórmula: NP = NPE/NPEV. O IR representa um método quantitativo que mostra a importância de uma espécie baseado em sua versatilidade no tratamento de doenças, sendo IR = 2 o valor máximo obtido por uma espécie (Macedo, 2013).

A diversidade de produtos medicinais comercializados pelos diferentes feirantes foi feita através do Índice de Diversidade de Shannon-Wiener (H') e o Índice de Equitabilidade de Pielou (J') (Krebs, 2000), no qual representam uma proporção do número de citações para uma determinada espécie/etnoespécie entre os diferentes feirantes. Estes índices são comumente utilizados para comparar a diversidade do conhecimento etnobotânico de diferentes comunidades (Begossi, 1996). 
A análise de diversidade foi gerada com auxílio do programa PAST, versão 1.4 (Hammer et al., 2001).

\section{Resultados e Discussão}

Foram identificadas um total de 169 espécies de plantas medicinais pertencentes a 100 famílias botânicas e 11 etnoespécies (Tabela 1; Figura 2). A família Fabaceae foi a mais representativa nas feiras livres das cidades. Resultados semelhantes foram registrados por Baptistel et al. (2014), no município de Currais, e de Lemos e Araújo (2015), no município de Luís Correia, ambas no estado do Piauí, onde 21,18\% e 13,11\%, respectivamente, das espécies identificadas pertenceram à família Fabaceae. Picos apresentou maior riqueza, com 83 espécies/etnoespécies com propriedades medicinais, distribuídas em 47 famílias. Destas, quatro não foram identificadas, sendo utilizado apenas os nomes populares conhecidos pelos feirantes como "saflor e/ou safroa", "tipi", "pau-doía" e "pau-chapada". As famílias com maior destaque foram Fabaceae (16,46\%) e Asteraceae $(7,59 \%)$. As demais famílias, de menor representatividade, obtiveram valores de 1,27\% a 5,06\%. A elevada riqueza de plantas medicinais em Picos era esperada, uma vez que a cidade se apresenta como polo para vários municípios circunvizinhos em diversos setores, dentre eles a feira livre, a qual funciona como centro de abastecimento e distribuição de produtos para diversas feiras livres das cidades vizinhas (Oliveira, 2011).

Figura 2. Algumas espécies de plantas medicinais comercializadas nas feiras livres das cidades de Jaicós, Paulistana e Picos PI. A - batata-de-purga; B - imburana-de-cheiro; C - cravo-da-índia; D - imbiriba; E - sucupira; F - gengibre; G - mororó; H romã; I - erva-doce; J - camomila; L - canela em casca; M - pau-ferro.

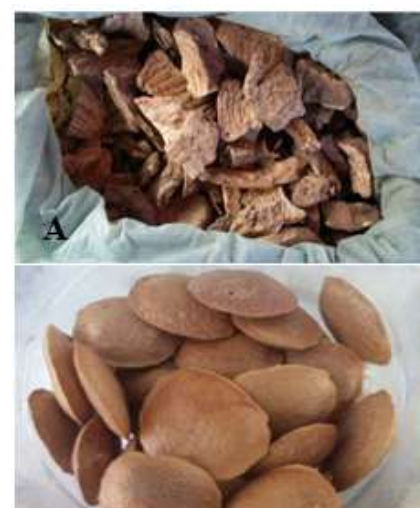

E

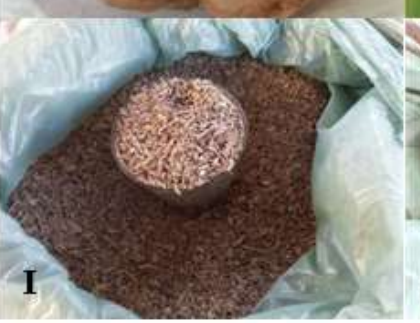

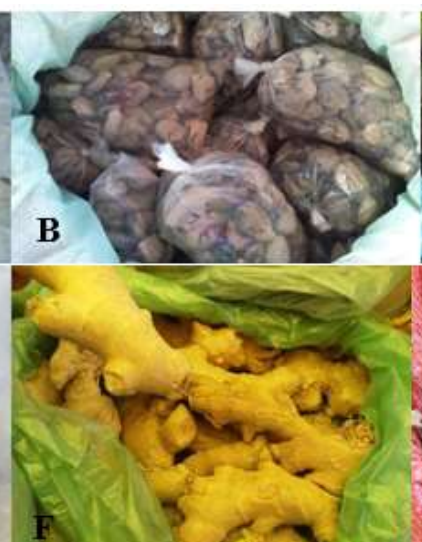
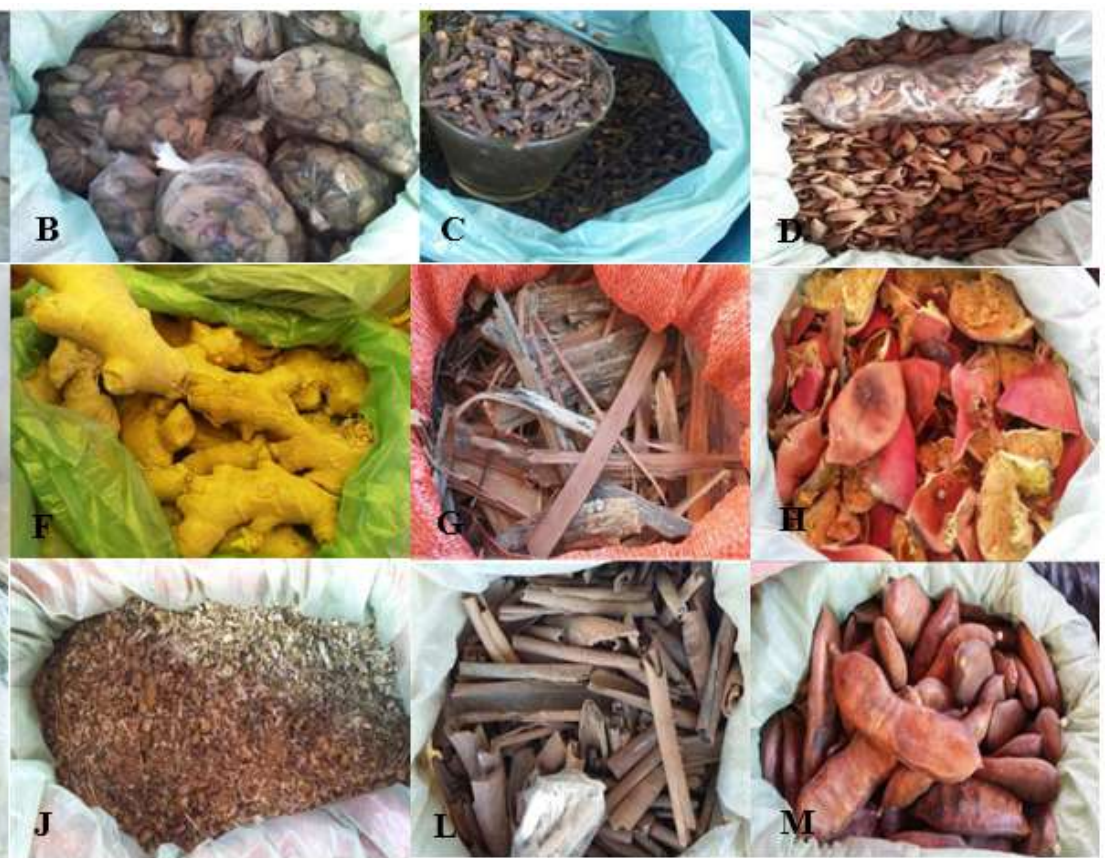

Fonte: Autores.

Apesar de ser a menor dentre as três cidades, a feira livre da cidade de Paulistana apresentou 64 espécies/etnoespécies, distribuídas em 32 famílias. Seis espécies não foram identificas, sendo tratadas como "costela-danta", "carrapicho-de-boi", "pau-chapada", "jarrinho e/ou millon", "chá-preto" e "saflor e/ou safroa". As famílias com maior destaque foram Fabaceae $(25,86 \%)$ e Apiaceae $(6,90 \%)$. As demais famílias tiveram valores variando de $1,72 \%$ a $5,17 \%$. Paulistana representa um centro comercial na microrregião do Alto Médio Canindé, o que movimenta um grande número de pessoas nos dias de feiras. É provável que o grande número de espécies/etnoespécies que são comercializadas em Paulistana deve-se ao fato da riqueza da flora local ou conhecimento tradicional associado que os feirantes possuem (Baptistel et al., 2014). 


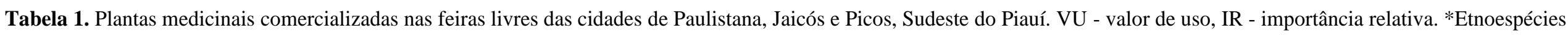
sem identificação.

\begin{tabular}{|c|c|c|c|c|c|c|c|c|c|}
\hline \multirow{2}{*}{ Família } & \multirow{2}{*}{ Nome científico } & \multirow{2}{*}{ Nome Popular } & \multirow{2}{*}{ Parte comercializada } & \multicolumn{2}{|c|}{ Jaicós } & \multicolumn{2}{|c|}{ Paulistana } & \multicolumn{2}{|c|}{ Picos } \\
\hline & & & & $\mathbf{V U}$ & IR & $\mathbf{V U}$ & IR & $\mathbf{V U}$ & IR \\
\hline Adoxaceae & Sambucus nigra $\mathrm{L}$. & Sabugueira & Folha & - & - & 0,60 & 0,67 & 0,11 & 0,37 \\
\hline Amaryllidaceae & Allium cepa $\mathrm{L}$. & Cebola branca & Bulbo & - & - & - & - & 0,11 & 0,37 \\
\hline Anacardiaceae & Myracrodruon urundeuva Allemão & Aroeira & Casca & - & - & 0,20 & 0,33 & 0,22 & 0,90 \\
\hline \multirow[t]{2}{*}{ Annonaceae } & Xylopia aromatica (Lam.) Mart. & Pimenta de macaco & Flor & - & - & 0,40 & 0,67 & - & - \\
\hline & Xylopia aromatica (Lam.) Mart. & Imbiriba & Partes do fruto & 0,63 & 1,25 & 0,80 & 1,83 & 0,67 & 1,43 \\
\hline \multirow[t]{5}{*}{ Apiaceae } & Centella asiatica (L.) Urb. & Centea asiática & Folha & - & - & - & - & 0,11 & 0,37 \\
\hline & Coriandrum sativum L. & Coentro & Sementes & 0,25 & 1,25 & 0,60 & 1,00 & 0,11 & 0,37 \\
\hline & Cuminum cyminum $\mathrm{L}$. & Cominho & Sementes & - & - & 0,20 & 0,33 & - & - \\
\hline & Anethum graveolens L. & Endro & Sementes & 0,38 & 2,00 & 0,60 & 1,33 & 0,33 & 1,47 \\
\hline & Pimpinella anisum $\mathrm{L}$. & Erva-doce & Sementes & 0,38 & 0,50 & 0,40 & 0,67 & 0,56 & 0,37 \\
\hline Arecaceae & Mauritia flexuosa $\mathrm{L} . \mathrm{f}$. & Buriti & Parte do fruto & 0,25 & 1,25 & 0,60 & 1,00 & 0,11 & 0,37 \\
\hline Aristolochiaceae & Aristolochia triangularis Cham. & Cipó mil-homem & Casca & - & - & - & - & 0,11 & 0,37 \\
\hline \multirow[t]{6}{*}{ Asteraceae } & Baccharis trimera (Less.) DC. & Marcela & Inflorescência & 0,63 & 1,50 & 0,80 & 0,67 & 0,67 & 0,73 \\
\hline & Cynara scolymus $\mathrm{L}$. & Carqueja & Caule/casca & - & - & - & - & 0,33 & 0,73 \\
\hline & Egletes viscosa (L.) Less. & Alcachofra & Folha & - & - & - & - & 0,22 & 0,90 \\
\hline & Helianthus annuиs $\mathrm{L}$. & Girassol & Sementes & - & - & 0,40 & 1,33 & 0,22 & 0,73 \\
\hline & Matricaria chamomila $\mathrm{L}$. & Camomila & Folha/flor & 0,25 & 0,50 & 1,00 & 1,00 & 0,89 & 0,37 \\
\hline & Taraxacum sp. & Dente de leão & Folha & - & - & - & - & 0,11 & 0,37 \\
\hline \multirow[t]{3}{*}{ Bignoniaceae } & Tabebuia sp. & Pau D’ Arco & Casca & 0,13 & 0,50 & 0,20 & 0,33 & - & - \\
\hline & Handroanthus impetiginosus (Mart. ex DC.) & Pau D'arco Roxo, ipê roxo & Casca & - & - & - & - & 0,22 & 0,73 \\
\hline & Mattos & & & & & & & & \\
\hline Boraginaceae & Cordia ecalyculata Vell. & Porangaba, aporangaba & Folha & - & - & - & - & 0,11 & 0,37 \\
\hline Brassicaceae & Brassica juncea (L.) Czern. & Mostarda & Sementes & 0,50 & 1,00 & 1,00 & 1,17 & 0,56 & 1,10 \\
\hline Cactaceae & Melocactus zehntneri (Britton \& Rose) Luetzelb. & Coroa de frade & Caule & - & - & - & - & 0,11 & 0,37 \\
\hline Caryocaraceae & Caryocar sp. & Pequi & Partes do fruto & 0,25 & 1,75 & 0,80 & 0,67 & 0,11 & 0,73 \\
\hline
\end{tabular}


Research, Society and Development, v. 10, n. 9, e25910917948, 2021

(CC BY 4.0) | ISSN 2525-3409 | DOI: http://dx.doi.org/10.33448/rsd-v10i9.17948

Celastraceae

Convolvulaceae

Compositae

Cucurbitáceas

Cunnoniaceae

Equisetaceae

Erythroxylaceae

Euphorbiaceae

Fabaceae
Maytenus ilicifolia Mart. ex Reissek

Operculina macrocarpa (L.) Urb.

$$
\text { Operculina sp. }
$$

Ipomoea purga (Wender.) Hayne

$$
\text { Arctium lappa } \mathrm{L} \text {. }
$$

Luffa operculata Cogn.

Lamanonia ternata Vell.

$$
\text { Equisetum hyemale } \mathrm{L} \text {. }
$$

Erythroxylum vacciniifolium Mart.

Croton rhamnifolioid_Pax \& K.Hoffm.

$$
\text { Croton grewioides Baill. }
$$

Ricinus communis $\mathrm{L}$.

Acacia farnesiana Wall.

Amburana cearensis (Allemão) A. C. Sm. Anadenanthera colubrina (Vell.) Brenan

$$
\text { Bauhinia sp. }
$$

Calliandra depauperata Benth.

$$
\text { Copaifera sp. }
$$

Enterolobium contortisiliquum (Vell.) Morong.

Erythrina velutina Willd.

$$
\text { Hymenaea sp. }
$$

Libidibia ferrea (Mart. ex Tul.) L.P.Queiroz

$$
\text { Medicago sativa } \mathrm{L} \text {. }
$$

$$
\text { Mimosa sp. }
$$

Mimosa tenuiflora (Willd.) Poir.

Pityrocarpa moniliformis Benth.) Luckow \&

$$
\text { R.W.Jobson }
$$

Poincianella pyramidalis (Tul.) L.P.Queiroz

Pterodon emarginatus Vogel.

\section{Espinheira santa \\ Batata de purga}

Batata de teiú, batata de tiú,

purga-de- lagarto

Jalapa
Bardana
Paulista, buchinha
Açoita-cavalo
Cavalinha
Catuaba
Quebra faca

Canelinha domato

$$
\text { Mamona }
$$

Corona, coronha

Imburana de cheiro Angico

Mororó, pata de vaca

Carquejo, carqueja

$$
\begin{gathered}
\text { Copaíba } \\
\text { Tamboril } \\
\text { Mulungu } \\
\text { Jatobá } \\
\text { Pau ferro } \\
\text { Alfafa } \\
\text { Unha de gato } \\
\text { Jurema preta }
\end{gathered}
$$

Angico Branco, angico de

$$
\text { bezerro }
$$

Catingueira

Sucupira

Folha

Raiz/semente

Raiz

Raiz

Folha

Partes do fruto

Folha/casca

Casca/folha

Casca

Casca

Casca

Sementes

Casca/semente

Casca

Casca

Casca

Partes do fruto

Casca

Casca

Casca

Sementes/casca

Folha

Casca

Casca

Casca

Casca

Sementes

$\begin{array}{cccccc}- & - & 0,40 & 0,50 & 0,22 & 0,73 \\ 0,13 & 0,75 & 0,80 & 0,83 & 0,33 & 1,27 \\ 0,13 & 0,50 & - & - & 0,11 & 0,73 \\ & & & & & \end{array}$

73

73 
Research, Society and Development, v. 10, n. 9, e25910917948, 2021

(CC BY 4.0) | ISSN 2525-3409 | DOI: http://dx.doi.org/10.33448/rsd-v10i9.17948

Senna alexandrina Mill.
Illiciaceae
Illicium verum Hook.f.
Iridaceae
Lamiaceae
Eleutherine bulbosa (Mill.) Urb.
Lavandula sp.
Melissa officinalis L.
Sabiatae
Lauraceae
Mentha piperita L.
Leguminosae
Rosmarinus officinalis L.
Liliaceae
Licaria puchury-major (Mart.) Kosterm.
Cinnamomum verum J. Presl
Melanoxylon brauna Schott.
Minaceae
Malvaceae
Mrimosaceae

Sene
Anil ou estrela da ema, flor
índia, anisío estrelado
Alho do mato
Alfazema
Erva-cidreira, capim cidrei
Chia
Hortelã
Alecrim
Pixuri
Canela em casca
Baraúna
Barbatimão
Alho
Babosa
Linhaça
Quiabo
Barriguda
Hibisco
Malva
Andiroba
Boldo
Noz-moscada
Inharé
Amora
Eucalipto
Cravo da índia
Marapuama
Amana, relógio

\begin{tabular}{|c|c|c|c|c|c|c|}
\hline Folha & 0,13 & 0,50 & 0,80 & 1,00 & 0,56 & 0,73 \\
\hline Flor/sementes & 0,25 & 1,00 & 0,80 & 0,83 & 0,33 & 0,70 \\
\hline Bulbo & 0,13 & 0,50 & - & - & 0,11 & 0,37 \\
\hline Flor & 0,13 & 1,00 & 0,40 & 0,67 & 0,22 & 0,37 \\
\hline Folha & - & - & - & - & 0,11 & 0,73 \\
\hline Sementes & - & - & 0,20 & 0,33 & 0,33 & 0,37 \\
\hline Folha & - & - & - & - & 0,22 & 0,90 \\
\hline Sementes & - & - & 0,40 & 1,33 & 0,22 & 1,271 \\
\hline Sementes & 0,38 & 2,00 & 0,80 & 0,67 & 0,44 & 0,90 \\
\hline Casca & 0,38 & 1,50 & 0,60 & 1,50 & 0,56 & 2,00 \\
\hline Casca & - & - & - & - & 0,11 & 0,73 \\
\hline Casca & - & - & 0,80 & 1,00 & 0,11 & 0,37 \\
\hline Bulbo & - & - & 0,40 & 0,67 & - & - \\
\hline Folha & - & - & - & - & 0,22 & 1,47 \\
\hline Sementes & - & - & 0,20 & 0,33 & 0,11 & 0,73 \\
\hline Sementes & - & - & 0,60 & 1,17 & - & - \\
\hline Casca & - & - & 0,20 & 1,00 & - & - \\
\hline Flor/folha/sementes & - & - & 0,40 & 0,33 & 0,44 & 0,90 \\
\hline Folha & - & - & - & - & 0,11 & 0,37 \\
\hline Partes do fruto & - & - & - & - & 0,11 & 0,73 \\
\hline Folha & 0,25 & 0,75 & 0,80 & 1,00 & 0,67 & 1,43 \\
\hline Sementes & 0,75 & 2,00 & 0,80 & 1,00 & 0,67 & 0,53 \\
\hline Folha & - & - & - & - & 0,11 & 0,37 \\
\hline Folha & - & - & - & - & 0,11 & 0,37 \\
\hline Folha & - & - & 0,60 & 0,67 & 0,22 & 1,27 \\
\hline Flor/sementes & 0,50 & 1,00 & 0,60 & 1,33 & 0,33 & 0,73 \\
\hline Casca & - & - & - & - & 0,11 & 0,37 \\
\hline Casca & - & - & 0,60 & 0,33 & 0,22 & 1,10 \\
\hline Raiz & - & - & - & - & 0,11 & 0,73 \\
\hline
\end{tabular}


Research, Society and Development, v. 10, n. 9, e25910917948, 2021

(CC BY 4.0) | ISSN 2525-3409 | DOI: http://dx.doi.org/10.33448/rsd-v10i9.17948

\begin{tabular}{|c|c|c|c|c|c|c|c|c|c|}
\hline Pedaliaceae & Sesamum indicum $\mathrm{L}$. & Gergelim preto & Sementes & 0,13 & 0,50 & - & - & - & - \\
\hline Poaceae & Cymbopogon citratus (DC.) Stapf. & Capim Santo, capim limão & Folha & - & - & - & - & 0,22 & 0,73 \\
\hline Punicaceae & Punica granatum Linn. & Romã & Fruto & - & - & 0,40 & 1,00 & 0,22 & 0,37 \\
\hline \multirow[t]{3}{*}{ Rhamnaceae } & Ziziphus joazeiro Mart. & Juazeiro & Casca & - & - & - & - & 0,11 & 0,73 \\
\hline & Coffea arabica $\mathrm{L}$. & Café & Semente & - & - & - & - & 0,11 & 0,37 \\
\hline & Chiococca alba (L.) Hitchc. & Canina ou cipó cruzeiro & Casca & 0,25 & 1,00 & - & - & - & - \\
\hline Rubiaceae & Coutarea hexandra (Jacq.) K. Schum. & Quina-quina & Casca & - & - & 0,80 & 0,83 & - & - \\
\hline Sapotaceae & Sideroxylon obtusifolium (Roem. \& Schult.) & Quixaba, quixabeira & Casca/raiz & - & - & 0,60 & 1,17 & 0,11 & 0,37 \\
\hline & T.D.Penn. & & & & & & & & \\
\hline Simaroubaceae & Picrasma sp & Pau tenente & Casca & - & - & - & - & 0,11 & 0,37 \\
\hline Solanaceae & Capsicum anпuит $\mathrm{L}$. & Pimenta caiena & Casca/semente & - & - & - & - & 0,11 & 0,37 \\
\hline Theaceae & Camellia sinensis (L.) Kuntze & Chá-verde & Folha & - & - & - & - & 0,33 & 0,73 \\
\hline Violaceae & Hybanthus calceolaria (L.) Oken & Papaconha & Raiz & - & - & - & - & 0,11 & 0,37 \\
\hline \multirow[t]{2}{*}{ Zingiberaceae } & Curcuma longa $\mathrm{L}$. & Açafrão & Caule & 0,13 & 1,25 & - & - & - & - \\
\hline & Zingiber officinale Roscoe & Gengibre & Caule & 0,13 & 1,00 & 0,60 & 0,83 & 0,22 & 0,73 \\
\hline \multirow[t]{8}{*}{ Etnoespécies* } & - & Pau chapada & Casca & 0,13 & 0,50 & 0,40 & 0,83 & 0,11 & 0,53 \\
\hline & - & Saflor & Caule & - & - & 0,20 & 0,50 & 0,11 & 0,37 \\
\hline & - & Tipi & Raiz & - & - & - & - & 0,11 & 0,37 \\
\hline & - & Pau doía & Casca & - & - & - & - & 0,11 & 0,37 \\
\hline & - & Costela danta & Casca & - & - & 0,20 & 0,67 & - & - \\
\hline & - & Carrapicho de boi & Raiz & - & - & 0,60 & 1,00 & - & - \\
\hline & - & Jarrinho/millon & Raiz & - & - & 0,40 & 0,67 & - & - \\
\hline & - & Chá-preto & Sementes & - & - & 0,60 & 1,00 & - & - \\
\hline
\end{tabular}

Fonte: Autores. 
Por outro lado, apenas 33 espécies/etnoespécies foram registradas em Jaicós, distribuídas em 20 famílias. Apenas "pauchapada" não foi identificado. As famílias com maior representatividade foram Fabaceae $(21,88 \%)$ e Apiaceae $(9,38 \%)$, as demais apresentaram valores de 3,13\% a 6,25\%. Apesar da proximidade entre Jaicós e Picos, as espécies não foram similares. Isso pode resultar do fato de que alguns feirantes apenas revendam os produtos obtidos de outras feiras e/ou possuírem pouco conhecimento acerca do potencial terapêutico que as plantas regionais possuem. Em função de fatores econômicos tem surgido nas feiras livres pessoas com pouca experiência atuando como vendedores de produtos fitoterápicos, o que pode resultar na descaracterização da figura do feirante livre de plantas medicinais "raizeiro", ou uma prescrição incorreta de sua função fitoterápica (Tresvenzol et al., 2006).

A cidade de Picos apresentou maior diversidade de espécies $\left(\mathrm{H}^{\prime}=4,159 ; \mathrm{J}^{\prime}=0,790\right)$ do que a cidade de Paulistana $\left(H^{\prime}=4,039 ; J^{\prime}=0,886\right)$ e Jaicós ( H'=3,312; J' = 0,831). Com exceção da cidade de Picos, os valores de diversidade $\left(H^{\prime}\right)$ registrados nas feiras de Jaicós e Paulistana foram inferiores aos registrados por Massarotto (2009) em um estudo realizado em comunidades quilombolas e áreas urbanas no estado de Goiás ( $\mathrm{H}^{\prime}$ variando de 4,15 a 4,70). Por outro lado, apresentaram valores superiores aos obtidos nos trabalhos de Rodal et al. (1998), Lemos e Rodal (2002), Oliveira Junior e Conceição (2012), realizados em regiões de Caatinga no Nordeste brasileiro (H' variando de 1,43 a 3,1).

O VU calculado (Tabela 1) permitiu determinar a importância das espécies a sua utilidade. As espécies imbiriba (Xylopia aromatica (Lam.) Mart.), marcela (Baccharis trimera (Less.) DC. (Less.) DC.) e noz-moscada (Myristica fagrans Houtt.) foram as que apresentaram os maiores VU. Imbiriba apresentou VU de 0,63, 0,80 e 0,67, marcela apresentou VU de 0,63, 0,80 e 0,67 e noz-moscada obteve VU de 0,75, 0,80 e 0,67 para Jaicós, Paulistana e Picos, respectivamente. Estes resultados diferem dos obtidos no trabalho de Franco e Barros (2006), para o município de Esperantina, estado do Piauí, no qual as espécies mussambê (Cleome spinosa L.), batata-de-purga (Operculina macrocarpa (L.) Farw.) e boldo (Coleus barbatus Benth.) obtiveram VU elevados (3,0, 2,0 e 1,6, respectivamente). No trabalho de Lemos e Araújo (2015), realizado no município de Luís Correia, também estado do Piauí, obtiveram VU de 3,0 para as espécies angelicó (Aristolochia triangularis Cham.), tipi (Petiveria alliaceae L.) e cataflam (Stachytarpheta cayennensis (LC Rich) Vahl Verbenaceae). Os valores da IR permitiram demonstrar a versatilidade de usos das espécies encontradas nas feiras livres, visto que, para determiná-las foram correlacionadas as indicações terapêuticas por sistemas corporais, conforme estabelecidos pela Organização Mundial de Saúde (OMS, 2015). As espécies mais versáteis (IR = 2,0) em Jaicós foram endro (Anethum graveolens L.), copaíba (Copaifera sp.), pixuri (Licaria puchury-major (Mart.) Kosterm.) e noz-moscada. Em Paulistana somente a espécie imburana-de-cheiro (Amburana cearensis (Allemão) A. C. Sm.) obteve valor máximo de IR. Por sua vez, em Picos, a espécie mais versátil foi canela em casca (Cinnamomum verum J. Presl). Estes resultados são opostos aos obtidos por Almeida e Albuquerque (2002), ao pesquisarem na feira livre da cidade de Caruaru, estado de Pernambuco, no qual a espécie que obteve o valor máximo de IR foi quixaba (Sideroxylon obtusifolium Humb. Roem. \& Schult.).

Um total de 577 citações de usos de plantas medicinais foram registradas (Tabela 2). As doenças com o maior número de citações foram gripe (54 citações; 9,7\%), ansiedade (39 citações; 7,0\%) e indigestão (37 citações; 6,6\%). Da mesma forma, as categorias de doenças com o maior número de citações foram sintomas e sinais gerais (116 citações; 43 espécies), doenças do aparelho respiratório (103 citações; 28 espécies) e doenças do aparelho digestivo (75 citações; 36 espécies). Semelhantes aos trabalhos de Medeiros et al. (2004), Souza e Felfili (2006) e Brasileiro et al. (2008), nos quais a doença com maior percentual de citação foi gripe com $22 \%, 19 \%$ e $18 \%$ das indicações, respectivamente. 


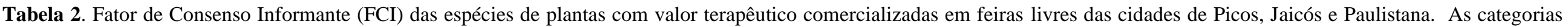
foram descritas de acordo a Organização Mundial de Saúde (OMS, 2015).

\begin{tabular}{|c|c|c|c|c|c|c|c|c|c|c|c|c|c|c|c|c|c|c|}
\hline \multicolumn{19}{|c|}{ Categorias* } \\
\hline & $\mathbf{A}$ & $\mathbf{B}$ & $\mathbf{C}$ & $\mathbf{D}$ & $\mathbf{E}$ & $\mathbf{F}$ & $\mathbf{G}$ & $\mathbf{H}$ & $\mathbf{I}$ & $\mathbf{J}$ & $\mathbf{L}$ & $\mathbf{M}$ & $\mathbf{N}$ & $\mathbf{O}$ & $\mathbf{P}$ & $\mathbf{Q}$ & $\mathbf{R}$ & $\mathbf{S}$ \\
\hline \multicolumn{19}{|l|}{ Jaicós - PI } \\
\hline Espécies utilizadas & 4,00 & 1,00 & 3,00 & 8,00 & 7,00 & 3,00 & 10,0 & 1,00 & - & - & 1,00 & - & 2,00 & - & - & 1,00 & 14,0 & 6,0 \\
\hline Porcentagem de espécies utilizadas (\%) & 12,1 & 3,03 & 9,09 & 24,2 & 21,2 & 9,09 & 30,3 & 3,03 & - & - & 3,03 & - & 6,06 & - & - & 3,03 & 42,4 & 18 , \\
\hline Citações de usos & 5,00 & 3,00 & 3,00 & 12,0 & 12,0 & 3,00 & 19,0 & 1,00 & - & - & 1,00 & - & 2,00 & - & - & 1,00 & 24,0 & 9,0 \\
\hline Porcentagem de citações de usos (\%) & 5,26 & 3,16 & 3,16 & 12,6 & 12,6 & 3,16 & 20,0 & 1,05 & - & - & 1,05 & - & 2,11 & - & - & 1,05 & 25,2 & 9,4 \\
\hline FCI & 0,25 & 1,00 & 0,00 & 0,36 & 0,45 & 0,00 & 0,50 & 0,00 & - & - & 0,00 & - & 0,00 & - & - & 0,00 & 0,43 & 0,3 \\
\hline \multicolumn{19}{|l|}{ Paulistana - PI } \\
\hline Espécies utilizadas & 10,0 & 1,00 & 11,0 & 14,0 & 22,0 & 13,0 & 20,0 & 1,00 & 2,00 & 5,00 & 8,00 & 3,00 & 7,00 & - & 3,00 & 1,00 & 21,0 & 7,0 \\
\hline Porcentagem de espécies utilizadas (\%) & 15,6 & 1,56 & 17,1 & 21,8 & 34,3 & 20,3 & 31,2 & 1,56 & 3,13 & 7,81 & 12,5 & 4,69 & 10,9 & - & 4,69 & 1,56 & 32,8 & 10 , \\
\hline Citações de usos & 13,0 & 2,00 & 19,0 & 19,0 & 35,0 & 14,0 & 46,0 & 1,00 & 2,00 & 7,00 & 14,0 & 3,00 & 11,0 & - & 4,00 & 1,00 & 36,0 & 14 , \\
\hline Porcentagem de citações de usos (\%) & 5,39 & 0,83 & 7,88 & 7,88 & 14,5 & 5,81 & 19,0 & 0,41 & 0,83 & 2,90 & 5,81 & 1,24 & 4,56 & - & 1,66 & 0,41 & 14,9 & 5,8 \\
\hline FCI & 0,25 & 1,00 & 0,44 & 0,28 & 0,38 & 0,08 & 0,58 & 0,00 & 0,00 & 0,33 & 0,46 & 0,00 & 0,40 & - & 0,33 & 0,00 & 0,43 & 0,5 \\
\hline \multicolumn{19}{|l|}{ Picos - PI } \\
\hline Espécies utilizadas & 7,00 & 1,00 & 2,00 & 10,0 & 15,0 & 16,0 & 20,0 & - & 1,00 & 2,00 & 11,0 & 2,00 & 10,0 & 1,00 & - & 2,00 & 28,0 & 10 , \\
\hline Porcentagem de espécies utilizadas (\%) & 8,43 & 1,20 & 2,41 & 12,0 & 18,0 & 19,2 & 24,1 & - & 1,20 & 2,41 & 13,2 & 2,41 & 12,0 & 1,20 & - & 2,41 & 33,7 & 12 , \\
\hline Citações de usos & 10,0 & 2,00 & 2,00 & 22,0 & 28,0 & 19,0 & 38,0 & - & 1,00 & 2,00 & 14,0 & 2,00 & 16,0 & 1,00 & - & 2,00 & 56,0 & 26 , \\
\hline Porcentagem de citações de usos (\%) & 4,15 & 0,83 & 0,83 & 9,13 & 11,6 & 7,88 & 15,7 & - & 0,41 & 0,83 & 5,81 & 0,83 & 6,64 & 0,41 & - & 0,83 & 23,2 & 10 , \\
\hline FCI & 0,33 & 1,00 & 0,00 & 0,57 & 0,48 & 0,17 & 0,49 & - & 0,00 & 0,00 & 0,23 & 0,00 & 0,40 & 0,00 & - & 0,00 & 0,51 & 0,6 \\
\hline
\end{tabular}

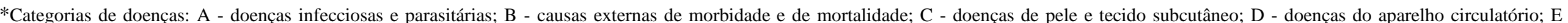

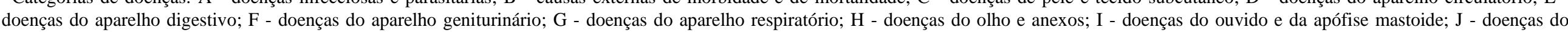

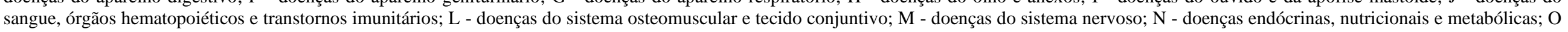
- gravidez, parto e puerpério; P - lesões, envenenamento e consequências de causas externas; Q - neoplasias; R - sintomas e sinais gerais; S: transtornos mentais e comportamentais. Fonte: Autores. 
As plantas medicinais registradas possuem indicação para o tratamento de 75 doenças ou sintomas (Tabela 3). As categorias com os maiores valores $\mathrm{FCI}$ foram: doenças do aparelho respiratório $(\mathrm{FCI}=0,58)$, transtornos mentais $\mathrm{e}$ comportamentais $(\mathrm{FCI}=0,64)$ e causas externas de morbidade e de mortalidade ( $\mathrm{FCI}=1,0)$. Resultados semelhantes ocorreram nos trabalhos de Amorozo (2002), Albuquerque et al. (2007) e Macêdo (2013). Estes trabalhos, realizados em comunidades rurais do nordeste brasileiro, registraram maior consenso no tratamento de doenças relacionadas ao aparelho respiratório. Diferem, no entanto, Almeida e Albuquerque (2002), no qual as doenças do ouvido apresentam maior valor de FCI.

Tabela 3. Categorias de doenças tratadas à base de plantas medicinais comercializadas em feiras livres das cidades de Jaicós, Paulistana e Picos, localizadas no Sudeste do Estado do Piauí, Nordeste do Brasil.

\begin{tabular}{clc}
\hline Categoria & \multicolumn{1}{c}{ Doenças citadas } & Total \\
\hline A & Sarampo, varicela ou catapora, diarreia, verminoses. & 04 \\
B & Mordida de cobra, picada de inseto, lesão com espinhos. & 03 \\
C & Cicatrizes subcutâneas, vitiligo, caspa. & 03 \\
D & Derrame ou AVC, hipertensão ou pressão alta, doenças cardíacas, circulação sanguínea, problemas & 07 \\
& de coração, infarto, doenças do sangue. & \\
E & Gastrite, indigestão, ressecamento intestinal ou intestino preso, dor de estômago, doenças de & 10 \\
& fígado, prisão de ventre, gastrite, hérnias, apendicite, infecção bucal. & 10 \\
F & Próstata, doenças do ovário e do útero, insuficiência renal, inflamação de urina, menopausa. & 05 \\
G & Gripe, catarro, resfriado, dor de garganta, bronquite, sinusite, doenças pulmonares, asma. & 08 \\
H & Pressão do olho, coceira no olho. & 02 \\
I & Labirintite, dor de ouvido. & 02 \\
J & Anemia, inflamação do baço. & 02 \\
L & Dor de coluna, osteoporose, dor em ossos, dores musculares, dores reumáticas. \\
M & Enxaqueca, epilepsia. & 05 \\
N & Diabetes, colesterol. & 02 \\
O & Pós-parto. & 02 \\
P & Alergias, coceiras. & 01 \\
Q & Câncer. & 02 \\
R & $\begin{array}{l}\text { Dor de cabeça ou cefaleia, dores no corpo, náuseas ou vômitos, tosse, gases, tontura ou } \\
\text { instabilidader emagrecimento, rouquidão, hematomas, emagrecimento, perda de memória, }\end{array}$ \\
S & cólica, febre ou convulsões e fraqueza. & 14 \\
\hline & Ansiedade, disfunção sexual ou impotência sexual. & 02 \\
\hline
\end{tabular}

*Categorias de doenças: A - doenças infecciosas e parasitárias; B - causas externas de morbidade e de mortalidade; C - doenças de pele e tecido subcutâneo; D - doenças do aparelho circulatório; E - doenças do aparelho digestivo; F - doenças do aparelho geniturinário; G doenças do aparelho respiratório; H - doenças do olho e anexos; I - doenças do ouvido e da apófise mastoide; J - doenças do sangue, órgãos hematopoiéticos e transtornos imunitários; L - doenças do sistema osteomuscular e tecido conjuntivo; $\mathrm{M}$ - doenças do sistema nervoso; $\mathrm{N}$ doenças endócrinas, nutricionais e metabólicas; O - gravidez, parto e puerpério; P - lesões, envenenamento e consequências de causas externas; Q - neoplasias; R - sintomas e sinais gerais; S: transtornos mentais e comportamentais. Fonte: Autores. 
Batata-de-purga, imburana-de-cheiro, pequi (Caryocar sp.), angico (Anadenanthera colubrina (Vell.) Brenan.), cravoda-índia (Syzygium aromaticum (L.) Merr. \& L.M.Perry), imbiriba, sucupira (Pterodon emarginatus Vogel) e gengibre (Zingiber officinale Roscoe) foram indicadas em todas as feiras para o tratamento de doenças relacionadas a categoria do aparelho respiratório. Tais resultados estão de acordo com os obtidos nos trabalhos de Moreira et al. (2002), Gomes et al. (2008), Oliveira Júnior e Conceição (2010) e Baptistel et al. (2014). Imbiriba pode ser usada também para o tratamento de doenças do aparelho digestivo (Pinto, 2008). A categoria transtornos mentais e comportamentais não foi mencionada até o momento em nenhum trabalho realizado no estado do Piauí. Erva-doce (Pimpinella anisum L.), endro e camomila (Matricaria chamomila $\mathrm{L}$.) foram as mais indicadas para o tratamento de doenças da categoria transtornos mentais e comportamentais nas três feiras pesquisadas. Tais espécies foram indicadas para o tratamento de diversas doenças, tendo maior destaque os transtornos de ansiedade. Resultados semelhantes foram observados por Macêdo et al. (2013), Santos (2014) e Souza et al. (2016), no qual destacaram a camomila como a mais indicada para problemas de ansiedade. Nesse contexto, existem testes comprovando a eficácia de princípios ativos presentes na camomila, demonstrando uma considerável redução na produção de cortisol em teste in vitro com seres humanos após a administração de apigenina (Ohno et al., 2002), sugerindo então que este princípio ativo inibe o surgimento do estresse e/ou ansiedade (Cassu et al., 2012).

Os fitoterápicos podem ser preparados a partir de diferentes partes da planta: semente, casca, fruto, folha, flor, raiz e caule (Franco \& Barros, 2006). Considerando as partes utilizadas, a semente $(32,0 \%)$ e a casca $(24,0 \%)$ foram as mais indicadas em Jaicós (Figura 3). Em Paulistana, no entanto, os mais indicados foram a casca (34\%) e as sementes (32,0\%) e na feira de Picos foi a casca $(29,0 \%)$ e as folhas $(26,0 \%)$. Neste caso, há um consenso na utilização da casca, ocupando a primeira posição em duas das três cidades, e a segunda posição na feira livre da cidade de Jaicós. Outros trabalhos corroboram a preferência na utilização de cascas, folhas e sementes nas regiões Norte e Nordeste do Brasil (Almeida \& Albuquerque, 2002; Freitas \& Fernandes, 2006; Albuquerque et al., 2007; Lima et al., 2011).

Figura 3. Gráfico das partes de plantas comercializadas nas feiras livres das cidades de Jaicós, Paulistana e Picos, Sudeste do Piauí.

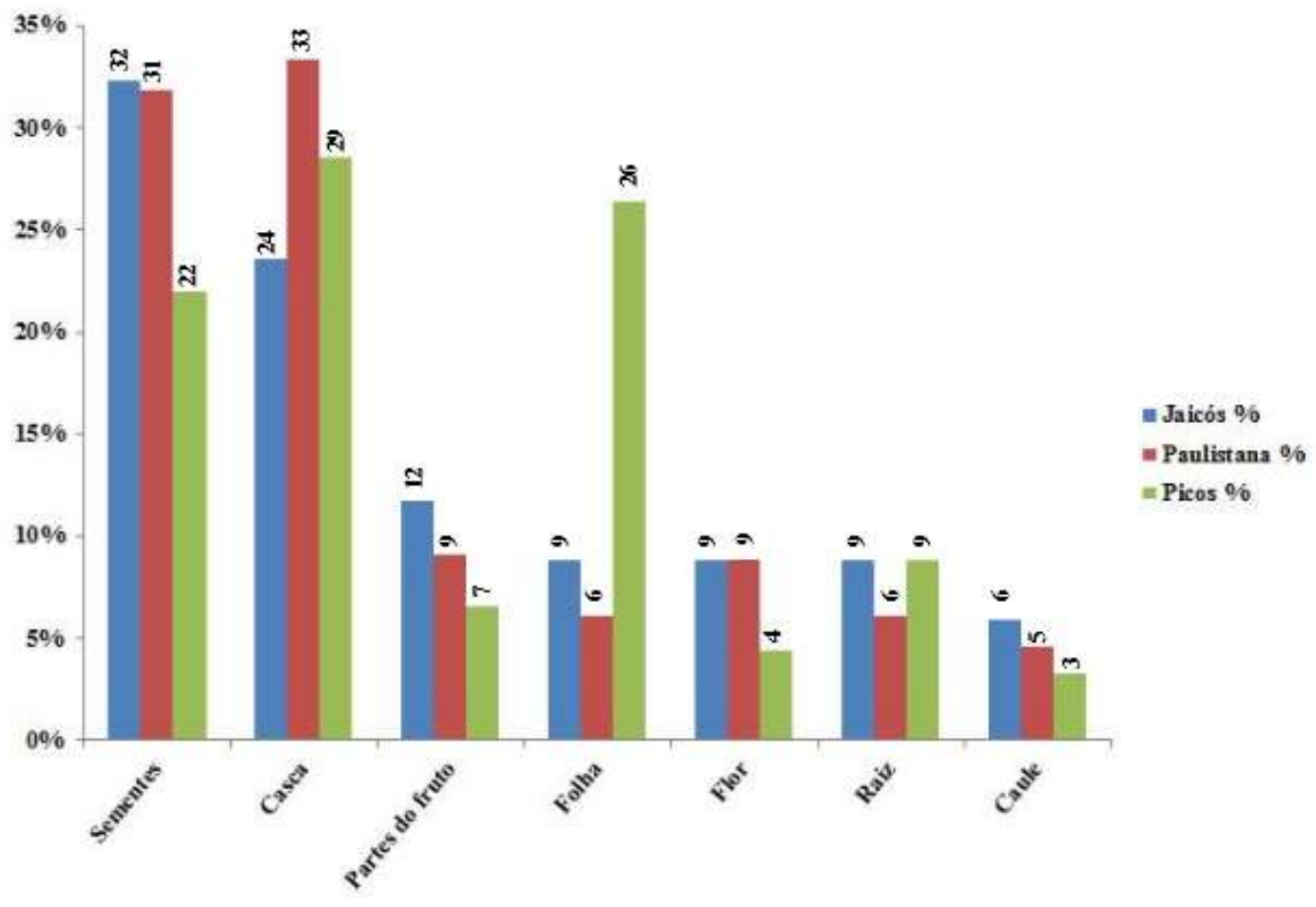

Fonte: Autores. 
No que se refere às partes de plantas que são comercializadas em feiras livres, a variação dos valores de comercialização de tais partes é resultante das peculiaridades de cada região, da cultura regional e, sobretudo da facilidade e/ou da disponibilidade para a realização da coleta de tais produtos (Albuquerque et al., 2007; Coelho-Ferreira, 2009). Uma das explicações para que cascas, folhas e sementes serem as partes mais comercializadas nas feiras livres das cidades pesquisadas pode estar relacionado às formas de armazenamento, visto que cascas, folhas e sementes podem ficar por longos períodos armazenados e serem de fácil conservação nas barracas (Lima et al., 2011).

\section{Considerações Finais}

Nesse contexto, conhecer a diversidade de espécies de plantas que têm propriedades fitoterápicas e que são comercializadas em feiras livres, é de fundamental importância para ações estratégicas que visam sua conservação, mantendo assim a disponibilidade de tais recursos e a continuidade dos conhecimentos tradicionais associados (Ferreira et al., 2012). Aqui foram registradas espécies e/ou etnoespécies de plantas que possuem propriedades medicinais indicadas para o tratamento de diversas doenças, dentre estas, algumas obtiveram consenso entre os feirantes livres na indicação para o tratamento de algumas enfermidades, tendo os valores de importância relativa calculado atingido valores significativos.

Dentro da dinâmica das três feiras livres pesquisadas, foi constatada a diversidade de enfermidades tratadas à base de plantas medicinais. As partes vegetais utilizadas no preparo de fitoterápicos e comercializadas nas feiras livres foram bem diversificadas, sendo que a casca foi o produto mais comercializado em duas das três feiras pesquisadas. Isto pode ser resultante da facilidade de obtenção deste produto, haja vista que se pode obtê-lo em qualquer época do ano e ser de fácil armazenamento. Dentro deste contexto, este foi o primeiro trabalho realizado em feiras livres no estado do Piauí, tendo buscado refletir a riqueza dos saberes populares aliado ao tratamento de enfermidades na medicina tradicional junto ao uso de plantas medicinais, bem como despertar para o surgimento de trabalhos futuros, sejam no aspecto etnobotânico e/ou farmacológico, pois foi constatada a elevada riqueza de espécies comercializadas e a diversidade de enfermidades citadas pelos feirantes. Também é fundamental chamar atenção para que ocorram mais ações estratégicas de cunho conservacionista, tanto dos recursos naturais como a continuidade dos saberes populares, pois a manutenção dos saberes populares de um povo é de vital importância para a preservação dos recursos naturais existentes.

\section{Agradecimentos}

Agradecemos a todos os participantes, em especial os feirantes das cidades pesquisadas, pela receptividade e disponibilidade em responder aos questionamentos. SCMA agradece à Universidade Estadual do Maranhão - UEMA pela concessão da bolsa mestrado (Chamada interna no 01/2020 - PPG/UEMA).

\section{Referências}

Albuquerque, U. P., Monteiro, J. M., Ramos, A. R. \& Amorim, E. L. C. (2007). Medicinal and magic plants from a public market in northeastern Brazil. Journal of Ethnopharmacology, 110(1), 76-91. https://doi.org/10.1016/j.jep.2006.09.010

Albuquerque, U. P., Soldati, G. T., Sieber, S. S., Ramos, M. A., SÁ, J. C. \& Souza, L. C. (2012). The use of plants in the medical system of the Fulni-ô people (NE Brazil): A perspective on age and gender. Journal of Ethnopharmacology, 133(2), 866-873. https://doi.org/10.1016/j.jep.2010.11.021

Almeida, C. F. C. B. R. (2008). Estratégia de vida e composição química como preditores do uso de plantas medicinais por comunidades locais na Caatinga. Dissertação de mestrado, Programa de Pós-Graduação em Biologia Vegetal. Universidade Federal de Pernambuco, Recife, Pernambuco.

Almeida, S. P. N. C. (2009). Fazendo a feira: estudo das artes de dizer, nutrir e fazer etnomatemático de feirantes e fregueses da feira livre do bairro Major Prates em Montes Claros. Dissertação de Mestrado em Educação, Programa de Pós-graduação em Desenvolvimento Social. Universidade Estadual de Montes Claros, Montes Claros, Minas Gerais.

Almeida, C. F. C. B. R. \& Albuquerque, U. P. (2002). Uso e conservação de plantas e animais medicinais no estado de Pernambuco (Nordeste do Brasil): um estudo de caso. Interciencia, 27(6), 276-285. 
Amorozo, M. C. M. (2002). Uso e diversidade de plantas medicinais em Santo Antônio do Laverger, MT, Brasil. Acta Botanica Brasilica, 16(2), 189-203. http://dx.doi.org/10.1590/S0102-33062002000200006

Baptistel, A. C., Coutinho, J. M. C. P., Lins Neto, E. M. F. \& Monteiro, J. M. (2014). Plantas medicinais utilizadas na Comunidade Santo Antônio, Currais, Sul do Piauí: um enfoque etnobotânico. Revista Brasileira de Plantas Medicinais, 16(2), 406-425. https://doi.org/10.1590/1983-084X/12_137

Brasileiro, B. G., Pizziolo, V. R., Matos, D. S., Germano, A. M. \& Jamal, C. M. (2008). Plantas medicinais utilizadas pela população atendida no" Programa de Saúde da Família", Governador Valadares, MG, Brasil. Revista Brasileira de Ciências Farmacêuticas, 4(4), 629-636. http://dx.doi.org/10.1590/S151693322008000400009

Begossi, A. (1996). Use of ecological methods in ethnobotany: diversity indices. Economic Botany, 50(3), 280-289. https://doi.org/10.1007/BF02907333

Bennett, B. C. \& Prance, G. T. (2000). Introduced plants in the indigenous pharmacopoeia of Northern South America. Economic Botany, 54(1), 90-102. https://doi.org/10.1007/BF02866603

Boechat, P. T. V. \& Santos, J. L. (2015). Feira livre: dinâmicas espaciais e relações identitárias. Geosaberes: Revista de Estudos Geoeducacionais, 6(3), 653665 .

BRASIL (2006) Ministério da Saúde: Secretaria de Atenção à Saúde e Departamento de Atenção Básica. Política Nacional de Práticas Integrativas e Complementares no SUS. Disponível em: http://189.28.128.100/dab/docs/publicacoes/geral/pnpic.pdf (Acessado em 23/07/2017).

Coelho-Ferreira, M. (2009). Medicinal knowledge and plant utilization in an Amazonian coastal community of Marudá, Pará State (Brazil). Journal of Ethnopharmacology, 126(1), 159-175. https://doi.org/10.1016/j.jep.2009.07.016

Cassu, R. N., Andreazi, C. D. \& Pereira, L. (2012). Efeito da Matricaria Chamomilla CH12 na Resposta de Estresse em Cães. Colloquium Agrariae, 7(2), 0107.

Di Stasi, L. C. (1996). Plantas medicinais: arte e ciência. Editora Unesp. 231 p.

Ferreira, F. S., Albuquerque, U. P., Coutinho, H. D. M., Almeida, W. O. \& Alves, R. R. N. (2012). The trade in medicinal animals in northeastern Brazil. Evidence-based Complementary and Alternative Medicine. Hindawiv, 2012, 1-20. https://doi.org/10.1155/2012/126938

Franco, E. A. P. \& Barros, R. F. M. (2006). Uso e diversidade de plantas medicinais no Quilombo Olho D’água dos Pires, Esperantina, Piauí. Revista Brasileira de Plantas Medicinais, 8(3), 78-88. https://doi.org/10.1590/1983-084X/12_137

Freitas, J. C. \& Fernandes, M. E. B. (2006). Uso de plantas medicinais pela comunidade de Enfarrusca, Bragança, Pará. Boletim do Museu Paraense Emílio Goeldi Ciências Naturais, 1(3), 11-26.

CEPRO - Fundação Centro de Pesquisas Econômicas e Sociais do Piauí (2016). Diagnósticos dos municípios. http://www.cepro.pi.gov.br/diagsoceco.php (Acessado em 13/07/ 2017).

Gomes, E. C., Barbosa, J., Vilar, F. C. R., Perez, J. O., Vilar, R. C., Freire, J. L. O., Lima, A. N. \& Dias, T. J. (2008). Plantas da caatinga de uso terapêutico levantamento etnobotânico. Engenharia Ambiental: Pesquisa e Tecnologia, 5(2), 74-85.

Hammer, Ø., Harper, D.A.T. \& Ryan, P. D. (2001). Past: Paleontological Statistics Software Package for Education and Data Analysis. Palaeontologia Electronica, 4(1), 1-9.

IBGE - Instituto Brasileiro de Geografia e Estatística. (2020). Cidades. https://cidades.ibge.gov.br/

Oliveira Júnior, S. R. \& Conceição, G. C. M. (2010). Espécies vegetais nativas do cerrado utilizadas como medicinais pela Comunidade Brejinho, Caxias, Maranhão, Brasil. Cadernos de Geociências, 7(2), 140-148.

Krebs, C. J. (2000). Ecological Methodology. Harper and Row Publishers, 29(1), 1-10. https://doi.org/10.1071/WR01074

Lemos, J. R. \& Araújo, J. L. (2015). Estudo etnobotânico sobre plantas medicinais na comunidade de Curral Velho, Luís Correia, Piauí, Brasil. Biotemas, 28(2), 125-136. https://doi.org/10.5007/2175-7925.2015v28n2p125

Lemos, J. R. \& Rodal, M. J. N. (2002). Fitossociologia do componente lenhoso de um trecho da vegetação de caatinga no Parque Nacional Serra da Capivara, Piauí, Brasil. Acta Botanica Brasilica, 16(1), 23-42. https://doi.org/10.1590/S0102-33062002000100005

Lima, P. G. C., Coelho-Ferreira, M. R. \& Oliveira, R. (2011). Plantas medicinais em feiras e mercados públicos do Distrito Florestal Sustentável da BR-163, estado do Pará, Brasil. Acta Botanica Brasilica, 25(2), 422-434. https://doi.org/10.1590/S0102-33062011000200018

Liporacci, H. S. N. \& Simão, D. G. (2013). Levantamento etnobotânico de plantas medicinais nos quintais do Bairro Novo Horizonte, Ituiutaba, MG. Revista Brasileira de Plantas Medicinais, 15(4), 529-540. https://doi.org/10.1590/S1516-05722013000400009

Lopes, G. A. D., Feliciano, L. M., Diniz, R. E. S. \& Alves, M. J. Q. F. (2010). Plantas medicinais: indicação popular de uso no tratamento de hipertensão arterial sistêmica (HAS). Revista Ciência em Extensão, 6(2), 143-155.

Macêdo, D. G. (2013). Bioprospecção, Disponibilidade e Conservação de Plantas Medicinais: Encrave de Cerrado na Chapada do Araripe, Nordeste do Brasil. Dissertação de Mestrado em Bioprospeç̧ão Molecular, Programa de Pós-graduação em Bioprospecção. Universidade Regional do Cariri, Crato, Ceará.

Macêdo, M. S., Ribeiro, D. A. \& Souza, M. M. A. (2013). Uso de Plantas Medicinais Cultivadas em Uma Área de Caatinga em Assaré-Ceará. Cadernos de Cultura e Ciência, 12(1), 36-45. https://doi.org/10.14295/cad.cult.cienc.v12i1.503 
Massarotto, N. P. (2009). Diversidade e uso de plantas medicinais por comunidades quilombolas Kalunga e Urbanas, Nordeste do Estado de Goiás. Dissertação de Mestrado, Programa de Mestrado em Ciências Florestais. Universidade de Brasília, Brasília, Distrito Federal.

Medeiros, M. F. T., Fonseca, V. S. \& Andreata, R. H. P. (2004). Plantas medicinais e seus usos pelos sitiantes da Reserva Rio das Pedras, Mangaratiba, RJ, Brasil. Acta Botanica Brasilica, 18(2), 391-399. https://doi.org/10.1590/S0102-33062004000200019

Moreira, R. C. T., Costa, L. C. B., Costa, R. C. S. \& Rocha, E. A. (2002). Abordagem etnobotânica acerca do uso de plantas medicinais na Vila Cachoeira, Ilhéus, Bahia, Brasil. Acta farmacêutica bonaerense, 21(3), 205-211.

Mowobi, G. G., Abubakar, S., Osuji, C., Etim, V. N., Ogechi, N. \& Egya, J. J. (2016). Ethnobotanical Survey of Medicinal Plants Used for the Treatment of Skin Disease in Keffi, Nigeria. American Journal of Phytomedicine and Clinical Therapeutics, 4(2), 73-90.

Nunes, G. P., Silva, M. F., Resende, U. M. \& Siqueira, J. M. (2003). Plantas medicinais comercializadas por raizeiros no Centro de Campo Grande, Mato Grosso do Sul. Revista Brasileira de Farmacognosia, 13(2), 83-92. https://doi.org/10.1590/S0102-695X2003000200004.

Ohno, S., Shinoda, S., Toyoshima, S., Nakazawa, H., Makino, T. \& Nakajin, S. (2002). Effects of flavonoid phytochemicals on cortisol production and on activities of steroidogenic enzymes in human adrenocortical H295R cells. The Journal of steroid biochemistry and molecular biology, 80(3), 355-363. https://doi.org/10.1016/s0960-0760(02)00021-3

Oliveira, G. P. (2011). Flexibilizando o trabalho: desigualdade de gênero, saúde e precarização das atividades das pessoas trabalhadoras na feira-livre de Picos-PI. Dissertação de Mestrado, Programa de Pós-Graduação em Serviço Social. Universidade Federal do Pernambuco, Recife, Pernambuco.

OMS - Organização Mundial de Saúde (2015). Classificação Estatística Internacional de Doenças e Problemas Relacionados à Saúde. 10ª edição. São Paulo: Editora da Universidade de São Paulo. 1200 p.

Pinto, L. N. (2008). Plantas medicinais utilizadas em comunidades do município de Igarapé-Miri. Dissertação de Mestrado, Programa de Pós-Graduação em Ciências Farmacêuticas. Universidade Federal do Pará, Belém, Pará.

Rodal, M. J. N., Andrade, K. V. A., Sales, M. F. \& Gomes, A. P. S. (1998). Fitossociologia do componente lenhoso de um refúgio vegetacional no município de Buíque, Pernambuco. Revista Brasileira de Biologia, 58(3), 517-526. https://doi.org/10.1590/S0034-71081998000300017

Rossato, S. C., Filho, H. F. L. \& Begossi, A. (1999). Ethnobotany of caiçaras of the Atlantic Forest Coast (Brazil). Economic Botany, 53(4), 387-395. https://doi.org/10.1007/BF02866716

Santos, J. H. (2014). Plantas medicinais utilizadas por usuários de uma Unidade Básica de Saúde em Campina Grande. Trabalho de conclusão de curso em Enfermagem. Universidade Estadual da Paraíba, Campina Grande, Paraíba.

Silva, P. A., Faria, L. A., Lima, C. \& Marcelo, J. (2014). O perfil dos raizeiros e a comercialização de plantas medicinais em feiras livres do município de Vitória da Conquista, Bahia. Exatas online, 5(2), 8-18.

Souza, A. D. Z., Heinem, H. M., Amestoy, S. C., Mendieta, M. C., Piriz, M. A. \& Heck, R. M. (2016). O Processo de trabalho dos enfermeiros da atenção primária e a Política Nacional de Plantas Medicinais/Fitoterápicos. Revista brasileira plantas medicinais, 18(2), 480-487. https://doi.org/10.1590/1983084X/15_176

Souza, C. D. \& Felfili, J. M. (2006). Uso de plantas medicinais na região de Alto Paraíso de Goiás, GO, Brasil. Acta Botanica Brasilica, 20 (1), $135-142$.

Souza, C. R. (2015). As feiras livres como lugares de produção cotidiana de saberes do trabalho e educação popular nas cidades: alguns horizontes teóricos e analíticos no campo trabalho- educação. Trabalho necessário, 22(13), 126-144.

Souza-Moreira, T. M., Salgado, H. R. N. \& Pietro, R. C. L. R. (2010). O Brasil no contexto de controle de qualidade de plantas medicinais. Revista Brasileira de Farmacognosia, 20(3), 435-440. http://dx.doi.org/10.1590/S0102-695X2010000300023

Tresvenzol, L. M., Paula, J. R., Ricardo, A. F., Ferreira, H. D. \& Zatta, D. T. (2006). Estudo sobre o comércio informal de plantas medicinais em Goiânia e cidades vizinhas. Revista Eletrônica de Farmácia, 3(1), 23-28. 